\title{
Four-Wave Mixing Crosstalk Suppression Based on the Pairing Combinations of Differently Linear-Polarized Optical Signals
}

\author{
Haider Abd, ${ }^{1}$ Norashidah Md. Din, ${ }^{1}$ M. H. Al-Mansoori, ${ }^{2}$ F. Abdullah, ${ }^{1}$ and H. A. Fadhil ${ }^{3}$ \\ ${ }^{1}$ Centre for Communication Services Convergence Technologies, College of Engineering, Universiti Tenaga Nasional, \\ Jalan Ikram-Uniten, 43000 Kajang, Malaysia \\ ${ }^{2}$ Faculty of Engineering, Sohar University, P.O. Box 44, PCI 311 Sohar, Oman \\ ${ }^{3}$ School of Computer Engineering, University Malaysia Perlis, Malaysia, 02600 Arau, Perlis, Malaysia
}

Correspondence should be addressed to Haider Abd; haiderlaser@yahoo.com and Norashidah Md. Din; norashidah@uniten.edu.my

Received 11 November 2013; Accepted 24 December 2013; Published 29 April 2014

Academic Editors: N. Zhao and W. Zou

Copyright (C) 2014 Haider Abd et al. This is an open access article distributed under the Creative Commons Attribution License, which permits unrestricted use, distribution, and reproduction in any medium, provided the original work is properly cited.

\begin{abstract}
A new approach to suppressing the four-wave mixing (FWM) crosstalk by using the pairing combinations of differently linearpolarized optical signals was investigated. The simulation was conducted using a four-channel system, and the total data rate was $40 \mathrm{~Gb} / \mathrm{s}$. A comparative study on the suppression of FWM for existing and suggested techniques was conducted by varying the input power from $2 \mathrm{dBm}$ to $14 \mathrm{dBm}$. The robustness of the proposed technique was examined with two types of optical fiber, namely, single-mode fiber (SMF) and dispersion-shifted fiber (DSF). The FWM power drastically reduced to less than -68 and $-25 \mathrm{dBm}$ at an input power of $14 \mathrm{dBm}$, when the polarization technique was conducted for SMF and DSF, respectively. With the conventional method, the FWM powers were, respectively, -56 and $-20 \mathrm{dBm}$. The system performance greatly improved with the proposed polarization approach, where the bit error rates (BERs) at the first channel were $2.57 \times 10^{-40}$ and $3.47 \times 10^{-29}$ at received powers of -4.90 and $-13.84 \mathrm{dBm}$ for SMF and DSF, respectively.
\end{abstract}

\section{Introduction}

Four-wave mixing (FWM) is one of the phenomena that may lower the effectiveness of the transmitted signal in wavelength division multiplexing (WDM) systems under dense channel spacing and low chromatic dispersion. In a WDM system with equally spaced channels, the new frequencies generated by FWM will drop at the channel frequencies and will introduce crosstalk [1-3]. The FWM effect is a result of the change in the intensity dependence of the refractive index of optical fiber.

Few reports and methods have been proposed for solving the problems associated with FWM. The examples of such methods are the use of nonzero dispersion fibers, relatively low channel counts, and unequal channel spacing techniques [4-6]. However, dispersion causes the distortion of the transmitted signals and needs to be compensated to achieve a long-haul system. As the channel count increases, more channels have to be confined to the erbium-doped fiber amplifier gain band by reducing the channel spacing. This condition increases the FWM effects and has a negative effect on the FWM suppression methods. Increased channel separation would prevent the implementation of a dense WDM. Similarly, reducing the levels of FWM crosstalk by choosing unequal channel frequency spacing may not be a practical option because this technique also needs additional optical bandwidth.

By contrast, orthogonal polarization has recently been found to reduce the FWM crosstalk. The FWM time average power strongly depends on the relative polarization states of the mixing channels. The researcher has reduced the FWM by randomly adjusting the polarization state of the adjacent channels to be orthogonal to one another [7-10]. Nevertheless, adjusting the polarization state randomly will not surely reduce the FWM crosstalk in all optical channels. Furthermore, the bit error rate (BER) may be not improved in all users because the orthogonal polarization does not include all channel interactions. 
In this work, we combined pairs of channels with different polarizations. The first channel was polarized by a linear polarization of $45^{\circ}$, while the second channel was polarized at $90^{\circ}$ away by a linear polarization of $\left(45^{\circ}+90^{\circ}\right)$. Both of the polarized channels were combined using a polarizer combiner. The proposed technique was investigated in both single-mode fiber (SMF) and dispersion-shifted fiber (DSF) with a $70 \mathrm{~km}$ fiber length and four channels. Through this approach, the FWM crosstalk significantly reduced and a good improvement was observed in system performance. The results confirm the robustness of the polarization technique against the FWM crosstalk and show that the FWM crosstalk has no dangerous influence on the system performance, even at a high value of input power.

\section{System Description and Theoretical Background}

Figures 1(a)-1(b) describe the proposed and conventional system configuration of the transmitter and receiver. At the transmitter part, the array of continuous wave lasers $\left(\mathrm{L}_{1}-\mathrm{L}_{4}\right)$ is used to generate the carrier signal. The frequency of the first user is set to $193 \mathrm{THz}$, and the spacing between each user is $100 \mathrm{GHz}$. Each user is modulated with a $10 \mathrm{~Gb} / \mathrm{s}$ data rate. Therefore, the total data rate of the system was $40 \mathrm{~Gb} / \mathrm{s}$. The array laser sources are connected to an external modulator. The external modulator comprised a Pseudo-Random Bit Sequence (PRBS), which is connected to a pulse generator to modulate the optical signals using an NRZ modulation format. It is then connected to the Mach-Zehnder modulator (MZM), which acts as an intensity modulator.

In the proposed system simulation, each two channels are linearly polarized $90^{\circ}$ apart and then combined together. As shown in Figure 1(a), the first channel is polarized using a linear polarization of $(\theta)$, while the second channel is polarized using a linear polarization of $\left(\theta+90^{\circ}\right)$. Each of the two channels is combined using a polarizer combiner that combines the two input signals to one output port. The polarization angle has been selected at $\theta=45^{\circ}$. Then, the four signals are collected using a polarizer combiner with a $0^{\circ}$ polarization angle. The combined signals pass through optical fiber with a $70 \mathrm{~km}$ length. In the conventional system Figure 1(b), the state of polarization of each transmitted channel is $0^{\circ}$. Two types of optical fiber were used such as SMF and DSF and the standard parameters of each one were in Table 1. At the receiver, the signal is demultiplexed. The signal is detected by a PIN photodiode for direct detection. It is then passed through the low-pass Bessel filter. Finally, the signal is then connected directly to the system performance analyzer, which is used to generate the graph.

The nonlinear light amplitude ENL describes the FWM light; FFWM $=F_{i}+F_{j}-F_{k}$. The total nonlinear amplitude is [10]:

$$
\begin{aligned}
E^{\mathrm{NL}}= & \eta\left|E_{1}(0)\right|\left|E_{2}(0)\right|\left|E_{3}(0)\right| \\
& \cdot\left(\left\langle S_{k} \mid S_{j}\right\rangle\left|S_{i}\right\rangle+\left\langle S_{k} \mid S_{i}\right\rangle\left|S_{j}\right\rangle\right),
\end{aligned}
$$

where $\left|E_{j}(0)\right|(j=A, B, C)$ are the amplitudes at $z=0$.

\begin{tabular}{|c|c|c|}
\hline Parameter & Unit & Values \\
\hline Fiber length, $L$ & $\mathrm{~km}$ & 70 for SMF \\
\hline Input power, $P_{i}$ & $\mathrm{dBm}$ & $\begin{array}{c}\text { Varied from } 2 \text { to } \\
14 \mathrm{dBm} \text { with step } \\
2 \mathrm{dBm}\end{array}$ \\
\hline Input frequencies, $f_{i}, f_{j}$ and $f_{k}$ & $\mathrm{THz}$ & 193 to 193.3 \\
\hline Channel spacing, $\Delta f$ & $\mathrm{GHz}$ & 100 \\
\hline \multicolumn{3}{|l|}{ Standard SMF G.652 } \\
\hline Dispersion, $D_{c}$ & $\mathrm{ps} / \mathrm{nm} \cdot \mathrm{km}$ & 17 \\
\hline Cross effective area, $A_{\text {eff }}$ & $\mu \mathrm{m}^{2}$ & 80 \\
\hline Dispersion slope & $\mathrm{ps} / \mathrm{nm}^{2} \cdot \mathrm{km}$ & 0.07 \\
\hline \multicolumn{3}{|l|}{ Standard DSF G.653 } \\
\hline Dispersion, $D_{c}$ & $\mathrm{ps} / \mathrm{nm} \cdot \mathrm{km}$ & 0.3 \\
\hline Cross effective area, $A_{\text {eff }}$ & $\mu \mathrm{m}^{2}$ & 50 \\
\hline Dispersion slope & $\mathrm{ps} / \mathrm{nm}^{2} \cdot \mathrm{km}$ & 0.075 \\
\hline Degeneracy factor, $D_{g}$ & - & 6 \\
\hline Third order susceptibility, $X_{111}$ & $\mathrm{~m}^{3} / \mathrm{w} \cdot \mathrm{s}$ & $6 \times 10^{-15}$ \\
\hline Refractive index, $n$ & - & 1.48 \\
\hline Speed of light, $c$ & $(\mathrm{~m} / \mathrm{s})$ & $3 \times 10^{8}$ \\
\hline Attenuation factor & $(\mathrm{dB} / \mathrm{km})$ & 0.2 \\
\hline Number of channel & - & 4 \\
\hline$K$, detector responsively & $\mathrm{A} \backslash \mathrm{W}$ & 0.8 \\
\hline Total data rate & $\mathrm{Gb} / \mathrm{s}$ & 40 \\
\hline Optical bandwidth, $B$ & $\mathrm{MHz}$ & 622 \\
\hline
\end{tabular}

TABLE 1: System simulation parameters.

Relative polarization states can be represented by normalized Jones vectors $|S\rangle j$, which are assumed to be maintained throughout the fiber. The orthogonal polarization effect on FWM efficiency can be classified into the following cases.

(1) For all waves identically polarized, $\left\langle S_{i} \mid S_{j}\right\rangle i \neq j=$ 1 , the value of $X_{111 r}^{2}=1$, and (1), for $i$ and $j$, can rewritten as

$$
\begin{gathered}
E^{\mathrm{NL}}=2 \eta\left|E_{1}(0)\right|\left|E_{2}(0)\right|\left|E_{3}(0)\right|, \\
\left|E^{\mathrm{NL}}\right|^{2}=4 \eta\left|E_{1}(0)\right|^{2}\left|E_{2}(0)\right|^{2}\left|E_{3}(0)\right|^{2} .
\end{gathered}
$$

(2) For the case of two waves being copolarized and the third being orthogonally polarized $\left(\left|S_{i}\right\rangle=\left|S_{j}\right\rangle \perp\right.$ $\left.\left|S_{k}\right\rangle\right)$; this means $\left\langle S_{k} \mid S_{j}\right\rangle=0,\left\langle S_{k} \mid S_{i}\right\rangle=0$, with the value of $X_{111 r}^{2}=0$.

(3) In the case of $\left|S_{i}\right\rangle=\left|S_{k}\right\rangle \perp\left|S_{j}\right\rangle$, both $\left\langle S_{i} \mid S_{j}\right\rangle=$ $0,\left\langle S_{i} \mid S_{k}\right\rangle=1$; in this case the value of $X_{111 r}^{2}=$ $1 / 4$, so the square of the nonlinear amplitude now becomes

$$
\left|E^{\mathrm{NL}}\right|^{2}=\eta\left|E_{1}(0)\right|^{2}\left|E_{2}(0)\right|^{2}\left|E_{3}(0)\right|^{2}
$$




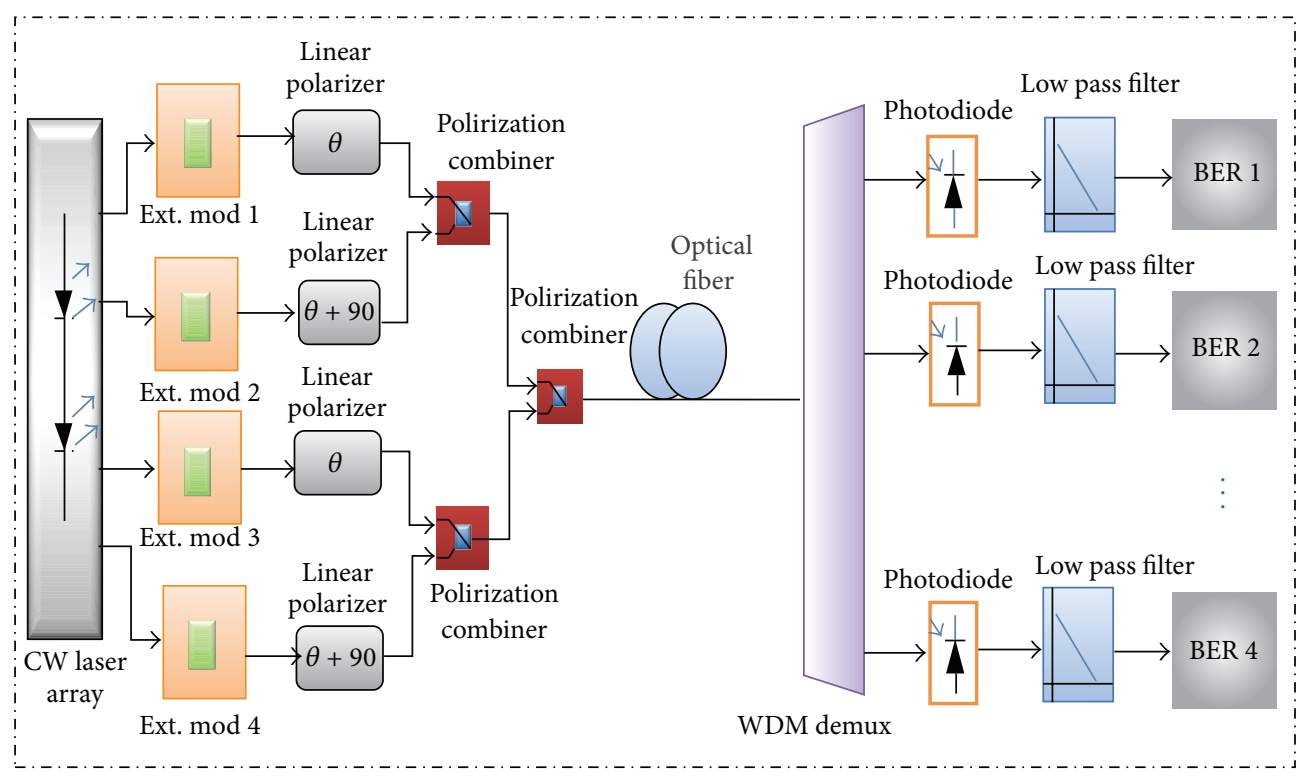

(a)

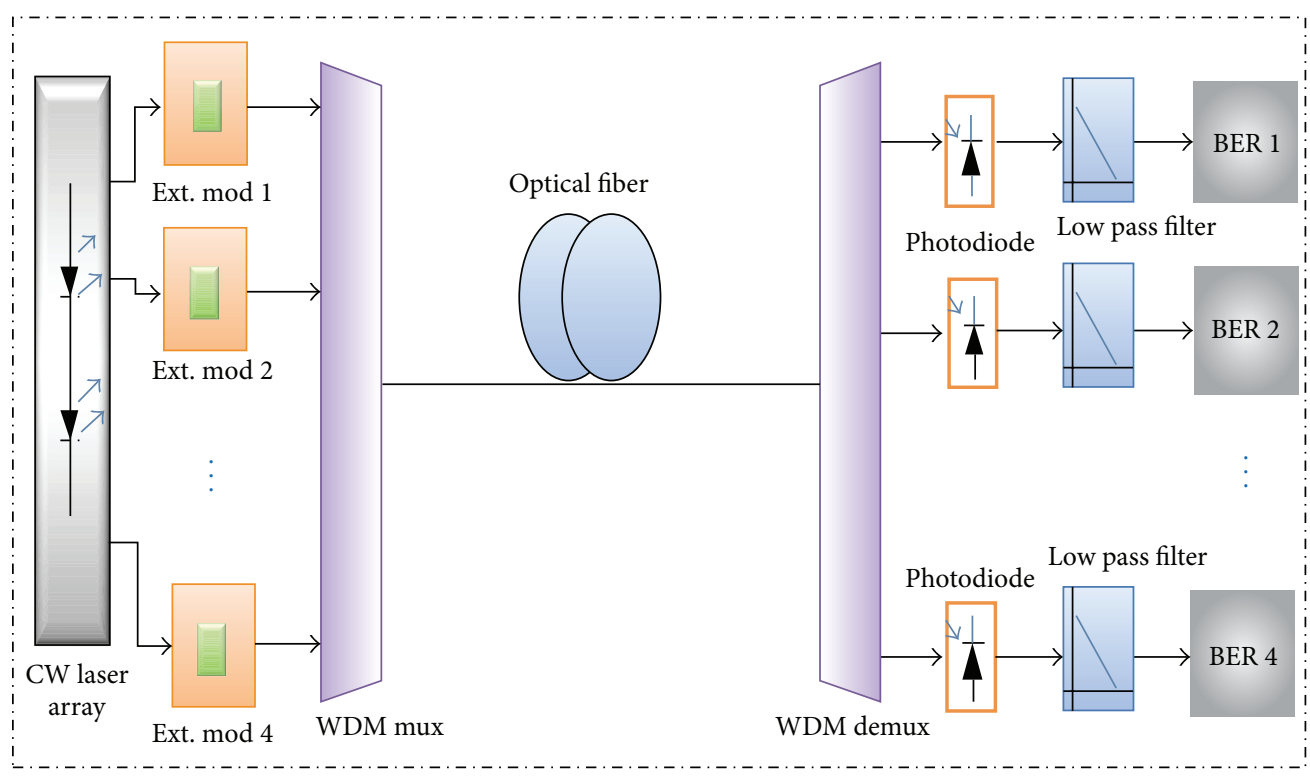

(b)

FIGURE 1: Optical system simulation configuration (a) proposed system and (b) conventional system.

In a WDM system, the power transferred to new frequencies due to FWM after light propagation within a distance $L$ in the fiber can be estimated using equation [11]:

$$
P_{\mathrm{FWM}}=\eta_{n} \times \frac{1024 \pi^{6}}{n_{r}^{4} \lambda^{2} C^{2}}\left(\frac{D X_{111} L_{\mathrm{eff}}}{A_{\mathrm{eff}}}\right)^{2}\left(P_{i} P_{j} P_{k}\right) e^{-\alpha L},
$$

where $P_{i}, P_{j}$, and $P_{k}$ are the input power values at central frequencies $f_{i}, f_{j}$, and $f_{k}$, respectively. $D$ is the degeneracy factor that is equal to 3 for two-tone and 6 for three-tone systems, $X_{111}$ is third-order susceptibility that is equal to $6 \times 10^{-15}\left(\mathrm{~m}^{3} /\right.$ w.s $), A_{\text {eff }}$ is the effective area, $C$ is the speed of light, $\lambda$ is the laser wavelength, $\alpha$ is the fiber loss coefficient, $L$ is the total fiber length, $n_{r}$ is the refractive index of the fiber, and $L_{\text {eff }}$ is the nonlinear effective length that can be calculated using the following equation:

$$
L_{\mathrm{eff}}=\frac{\left(1-e^{-\alpha L}\right)}{\alpha} .
$$

The efficiency $(\eta)$ of four-wave mixing is given by [3]

$$
\eta=\frac{\alpha^{2}}{\alpha^{2}+\Delta \beta^{2}}\left(1+\frac{4 e^{-\alpha L} \sin ^{2}(\Delta \beta L / 2)}{\left[1-e^{-\alpha L}\right]^{2}}\right),
$$




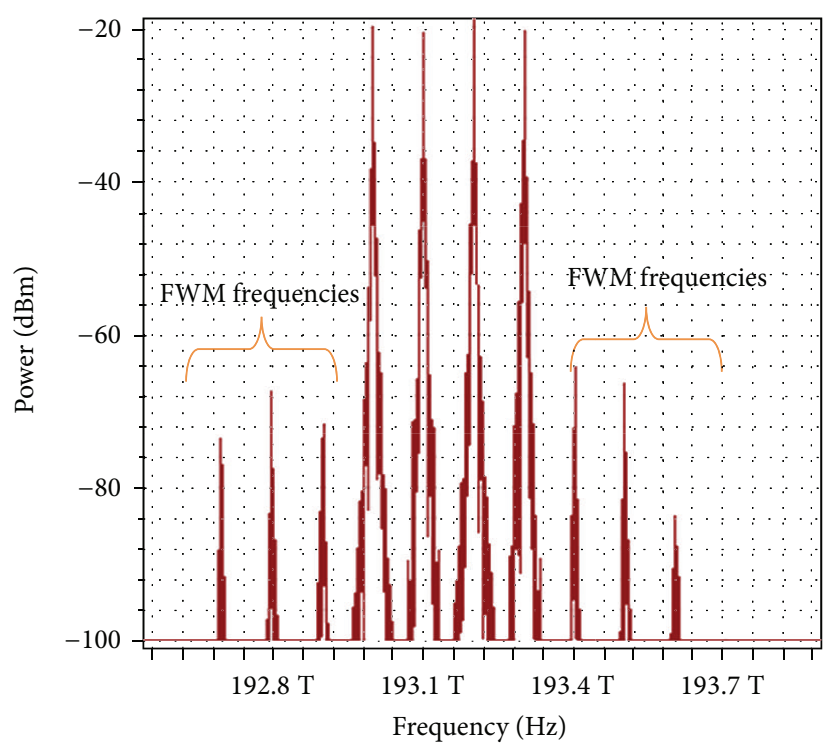

(a)

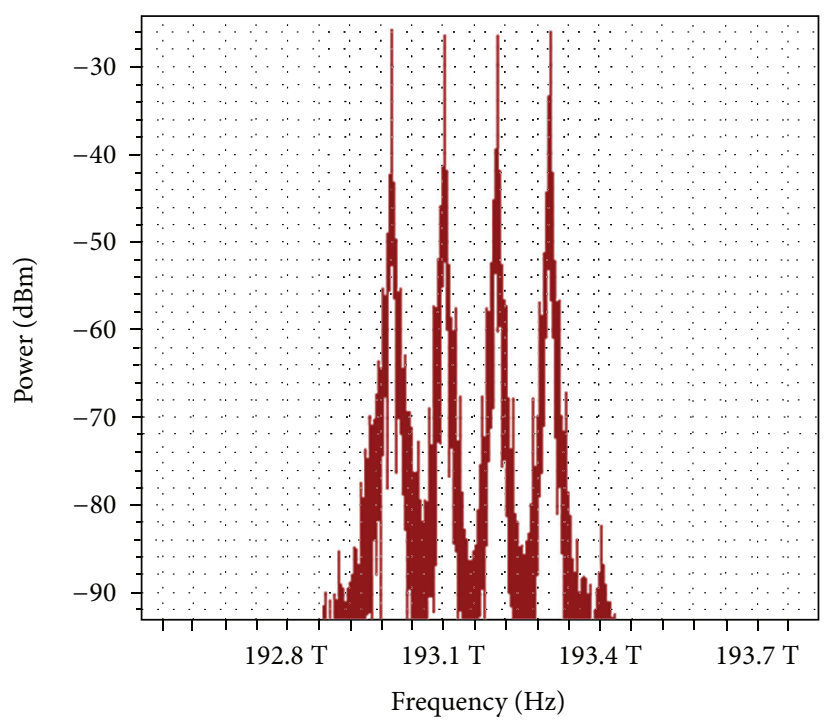

(c)

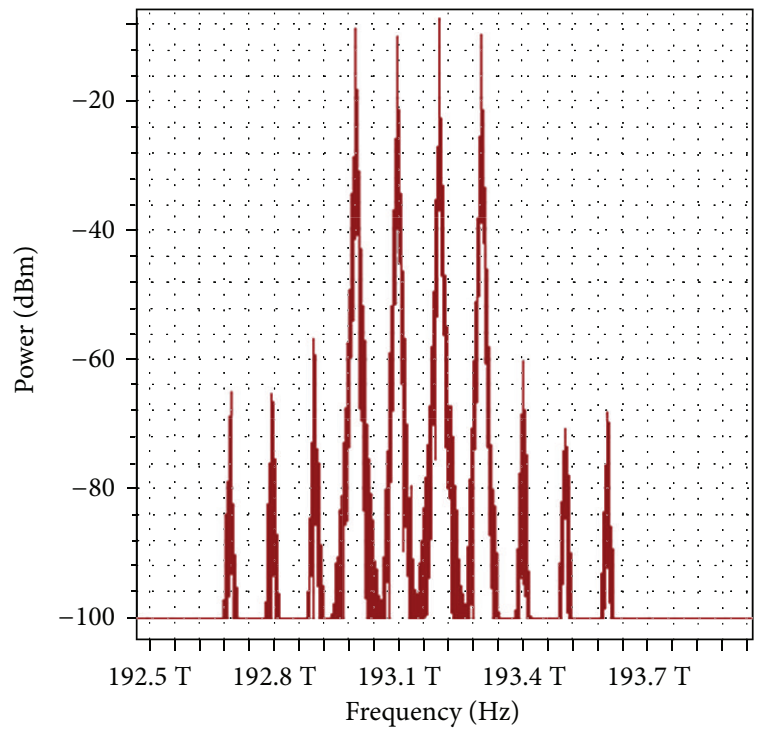

(b)

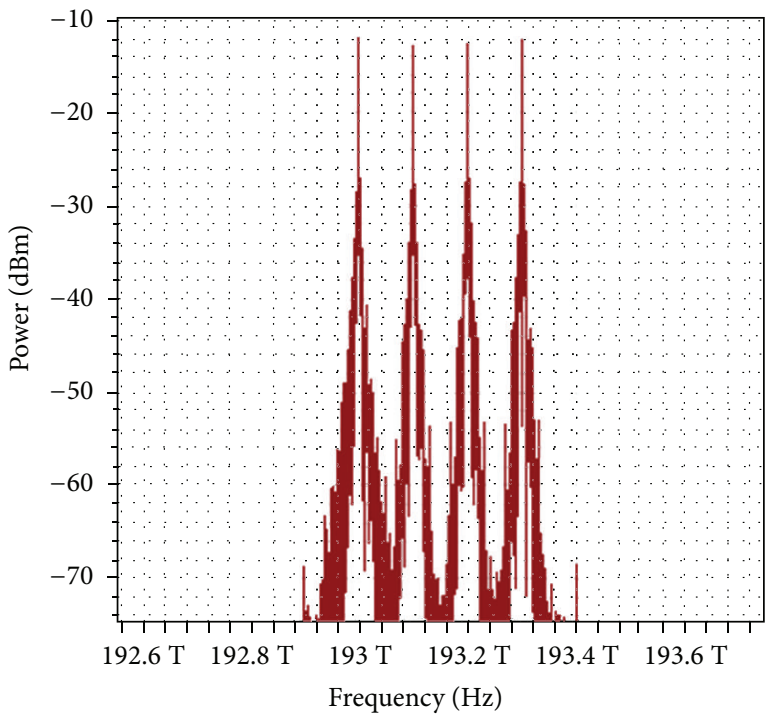

(d)

FIGURE 2: Optical spectrum comparison after $70 \mathrm{~km}$ SMF (a) without polarization technique at input power of $2 \mathrm{dBm}$, (b) without polarization technique at input power of $14 \mathrm{dBm}$, (c) with polarization technique at input power of $2 \mathrm{dBm}$, and (d) with polarization technique at input power $14 \mathrm{dBm}$.

where $\Delta \beta$ represents the phase mismatch and may be expressed in terms of signal frequency differences:

$$
\begin{aligned}
\Delta \beta= & \frac{2 \pi \lambda^{2}}{c}\left|f_{i}-f_{k}\right|\left|f_{j}-f_{k}\right| \\
& \times\left(D_{C}+\frac{d D}{d \lambda}\left(\frac{\lambda^{2}}{2 c}\right)\left(\left|f_{i}-f_{k}\right|+\left|f_{j}-f_{k}\right|\right)\right),
\end{aligned}
$$

where $D_{C}$ is the fiber chromatic dispersion and $d D / d \lambda$ is a derivative dispersion coefficient of the optical fiber. The right term of (6) and (7) has small and negligible values.
The general equation of FWM power can be summarized as follows:

$$
\begin{aligned}
P_{\mathrm{FWM}}= & \frac{1024 \pi^{6}}{n^{4} \lambda^{2} C^{2}}\left(\frac{D_{g} X_{111} L_{\mathrm{eff}}}{A_{\mathrm{eff}}}\right)^{2}\left(P_{i} P_{j} P_{k}\right) \\
& \times e^{-\alpha L} \frac{\alpha^{2}}{c \alpha^{2}+2 \pi D_{c}\left(\Delta f_{i k}\right)\left(\Delta f_{j k}\right)},
\end{aligned}
$$

where $\left(\Delta f_{i k}, \Delta f_{j k}\right)$ is the channel spacing.

Under the effect of polarization, FWM efficiency becomes

$$
\eta_{\mathrm{FWM}(\text { polirization })}=\frac{1}{N} \times \eta_{n} \times X_{111 r}^{2},
$$




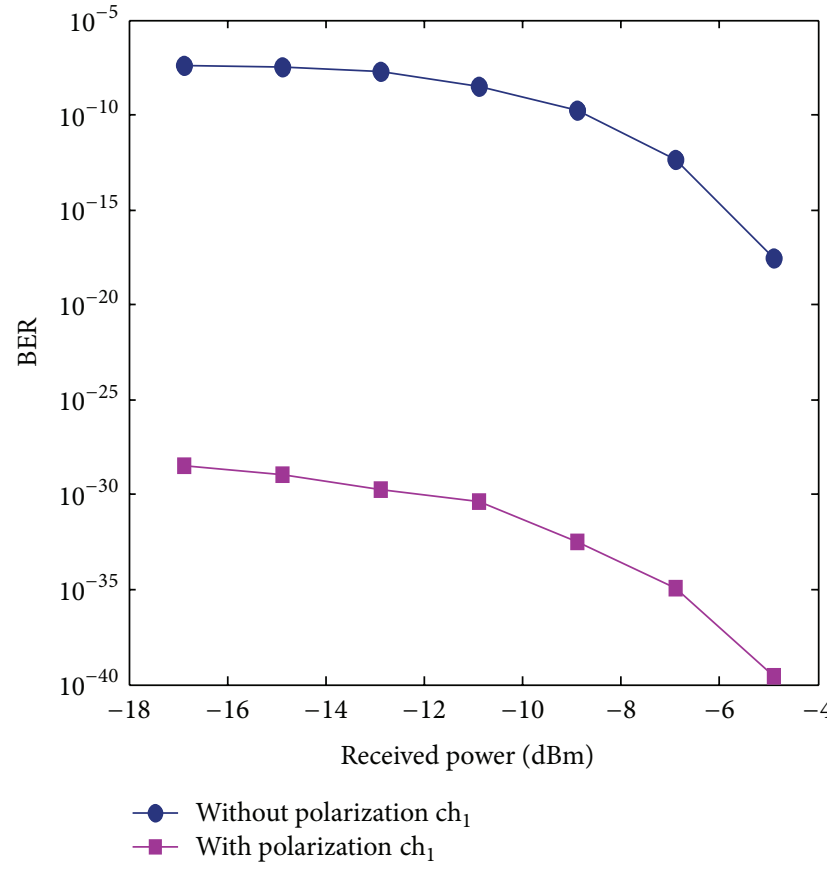

(a)

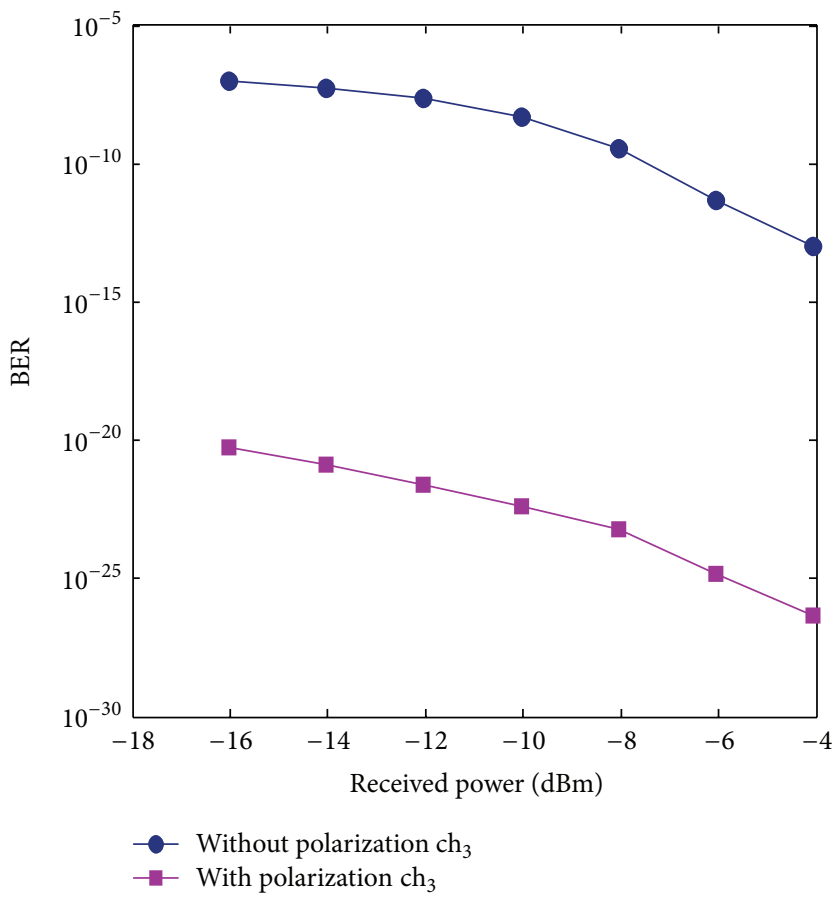

(c)

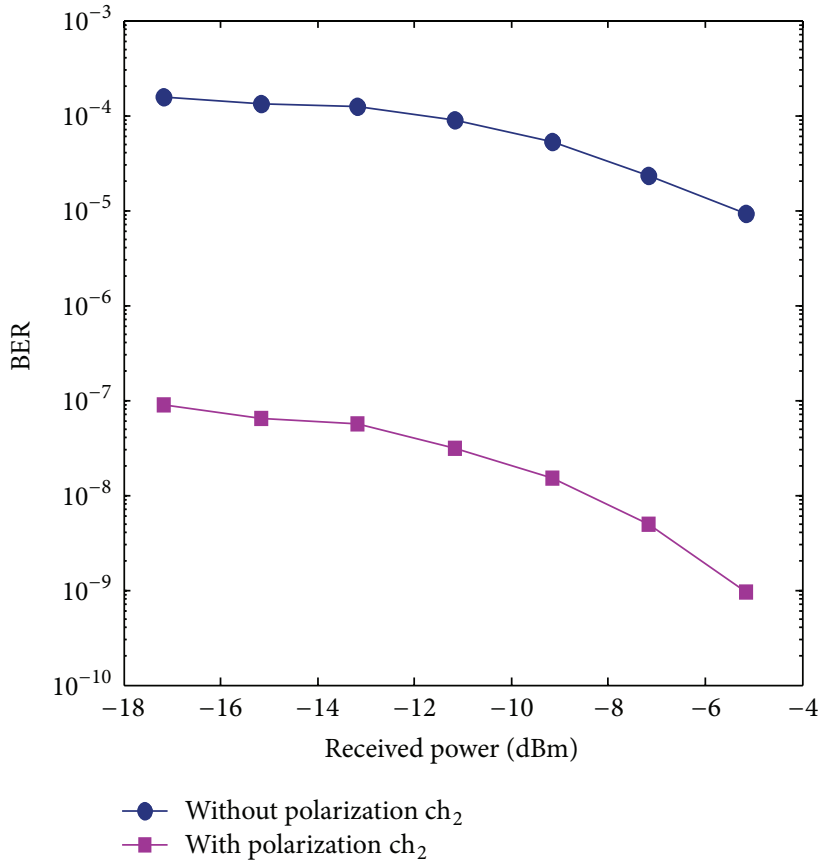

(b)

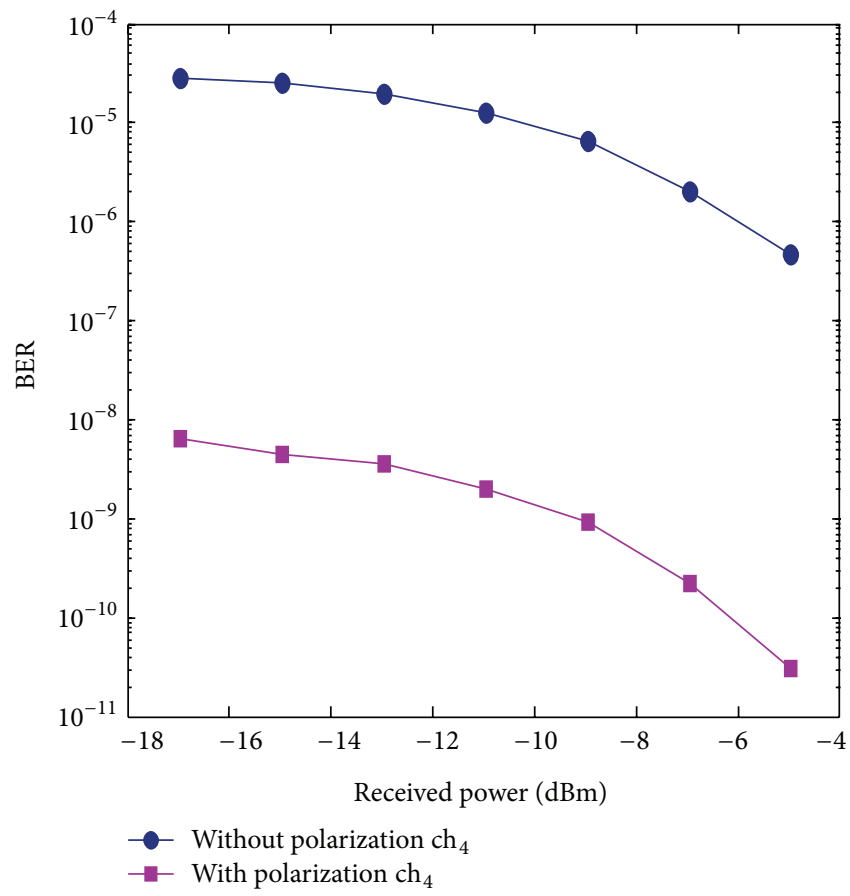

(d)

FIGURE 3: Received power versus BER in the presence and absence of the polarization techniques at (a) $\mathrm{ch}_{1}$, (b) $\mathrm{ch}_{2}$, (c) $\mathrm{ch}_{3}$, and (d) $\mathrm{ch}_{4}$.

where $\eta_{\mathrm{FWM}(\text { polarized) }}$ is FWM efficiency attained by polarization technique. $X_{1111 r}$ is a factor that represents polarization dependency of the FWM process and changes from 0 to 1 according to SOP between channels, as shown in (1) to (3).

$N$ is the total number of channel and $\eta_{n}$ is the FWM efficiency in the conventional system.
Using (8), FWM efficiency $\left(\eta_{n}\right)$ can be rewritten as follows:

$$
\eta_{n}=\frac{\alpha^{2}}{c \alpha^{2}+2 \pi D_{C}\left(\Delta f_{i k}\right)\left(\Delta f_{j k}\right)} .
$$




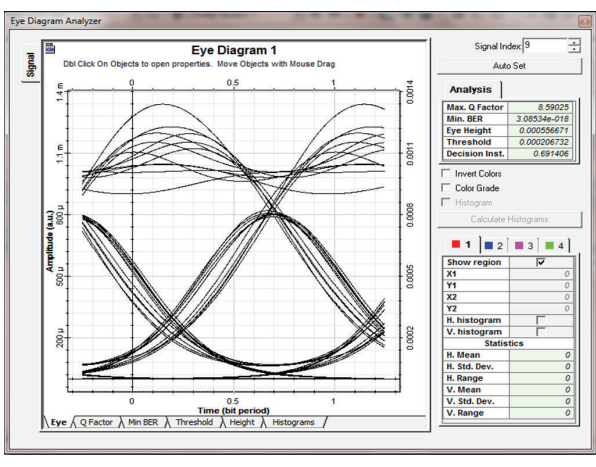

(a)

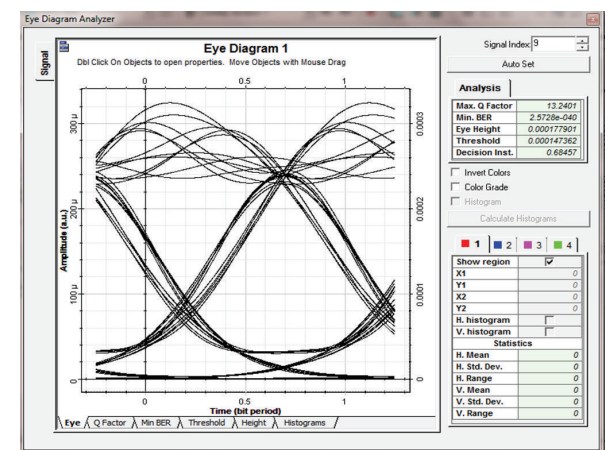

(b)

FIGURE 4: Optimum eye diagram performance of SMF using $\mathrm{ch}_{1}$ (a) without polarization technique and $(\mathrm{b})$ with polarization. Both at $P_{\text {in }}=$ $14 \mathrm{dBm}$.

By substituting (10) into (9), we can derive (11) as the following:

$$
\eta_{\mathrm{FWM}(\text { polirized })}=\frac{1}{N} \times \frac{X_{111 r}^{2} \times \alpha^{2}}{c \alpha^{2}+2 \pi D_{C}\left(\Delta f_{i k}\right)\left(\Delta f_{j k}\right)} .
$$

With the polarization effect, FWM power in (8) can be modified as follows:

$$
\begin{aligned}
P_{\text {FWM(poarized) }}= & \frac{1024 \pi^{6}}{n^{4} \lambda^{2} C^{2}}\left(\frac{D X_{111} L_{\text {eff }}}{A_{\text {eff }}}\right)^{2}\left(P_{i} P_{j} P_{k}\right) e^{-\alpha L} \\
& \times \eta_{\text {FWM(polarized) }} .
\end{aligned}
$$

By substituting (11) into (12), the general FWM power is as follows:

$$
\begin{aligned}
P_{\mathrm{FWM}(\text { polirized })}= & \frac{1024 \pi^{6}}{n^{4} \lambda^{2} C^{2}}\left(\frac{D X_{111} L_{\mathrm{eff}}}{A_{\mathrm{eff}}}\right)^{2}\left(P_{i} P_{j} P_{k}\right) e^{-\alpha L} \\
& \times \frac{X_{111 r}^{2} \times \alpha^{2}}{N \times\left(c \alpha^{2}+2 \pi D_{C}\left(\Delta f_{i k}\right)\left(\Delta f_{j k}\right)\right)} .
\end{aligned}
$$

In the Gaussian approximation, $[8,9]$, error probability is written as

$$
P_{e}=\frac{1}{\sqrt{2 \pi}} \int_{Q}^{\infty} \exp \left[-\frac{t^{2}}{2}\right] d t
$$

To calculate system performance under the effect of FWM, shot, and thermal noises, we used the following equations:

$$
\begin{gathered}
Q=\frac{K P_{S}}{\sqrt{N_{\mathrm{th}}+N_{\mathrm{sh}}+2 K^{2} P s^{2}} C_{\mathrm{IM}}^{(m)}+\sqrt{N_{\mathrm{th}}}}, \\
C_{\mathrm{IM}}^{(m)}=\frac{1}{8} \sum_{\mathrm{I}} \frac{P_{i j k}}{P_{s}}+\frac{1}{4} \sum_{\mathrm{III}} \frac{P_{i i k}}{P_{s}}
\end{gathered}
$$

where $Q$ is the $Q$ factor, $C_{\mathrm{IM}}^{(m)}$ is the effective FWM crosstalk in intensity modulation-direct modulation transmission, $P_{i j k}$ is the FWM power generated at frequency fs from a frequency combination satisfying $f_{i}+f_{j}-f_{k}=f_{s}$, where $f_{k}=f_{s}, P_{i i k}$ is the FWM power at identical $i$ and $j$, where $i=j \neq k, P_{s}$ is the received power at the receiver, $e$ is the electron charge $\left(1.6 \times 10^{-19} \mathrm{C}\right), N_{\text {th }}$ is thermal noise, and $N_{\text {sh }}$ is the shot noise.

To calculate the received power and to achieve a given BER $=10^{-9}, Q=6$, without FWM, and $C_{\mathrm{IM}}^{(m)}=0,(15)$ is modified as follows:

$$
\begin{gathered}
2 K^{2} P_{s}^{2} C_{\mathrm{IM}}^{(m)}+N_{\mathrm{th}}+N_{\mathrm{sh}}=\frac{K^{2} P_{s}^{2}}{Q^{2}}-2 \sqrt{N_{\mathrm{th}}} \frac{K P_{s}}{Q}+N_{\mathrm{th}}, \\
P_{S 0}=\frac{Q^{2}}{K}\left[2 B e+2 \frac{\sqrt{N_{\mathrm{th}}}}{Q}\right] .
\end{gathered}
$$

The effect of shot and thermal noises can be neglected because these noises have smaller values than those of FWM noise. $Q$ can be obtained using (15) as follows:

$$
\begin{gathered}
Q=\frac{K P_{S}}{\sqrt{2 K^{2} P s^{2} C_{\mathrm{IM}}^{(m)}}}, \\
Q^{2}=\frac{K^{2} P_{s}^{2}}{2 K^{2} P_{S}^{2} C_{(\mathrm{IM})}^{(m)}}=\frac{1}{2 C_{(\mathrm{IM})}^{(m)}}, \\
Q=\sqrt{\frac{1}{2 C_{(\mathrm{IM})}^{(m)}}} .
\end{gathered}
$$

BER is calculated using the following equation:

$$
\mathrm{BER}=0.5 \times \operatorname{erfc}\left[\frac{\mathrm{Q}}{\sqrt{2}}\right] .
$$

\section{Analysis Results and Discussions}

The proposed polarization technique was compared with the conventional method (without using the polarization) and examined with SMF and DSF. The comparison was conducted at an input power range of $2 \mathrm{dBm}$ to $14 \mathrm{dBm}$ as follows.

3.1. Effect of Proposed Technique on FWM Behavior and $B E R$ Using SMF. The simulation for a standard single-mode 


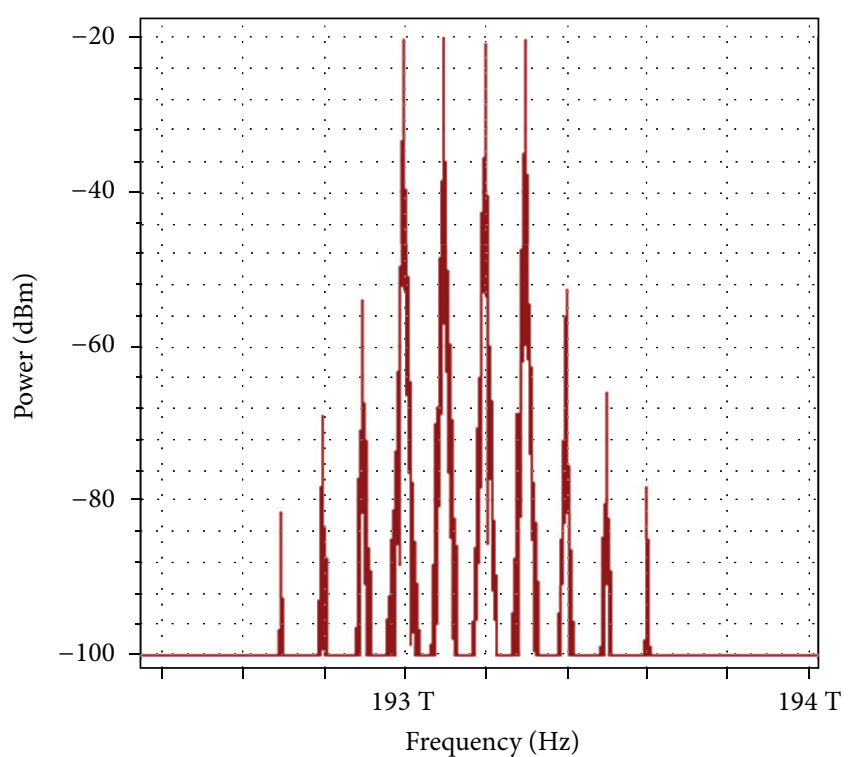

(a)

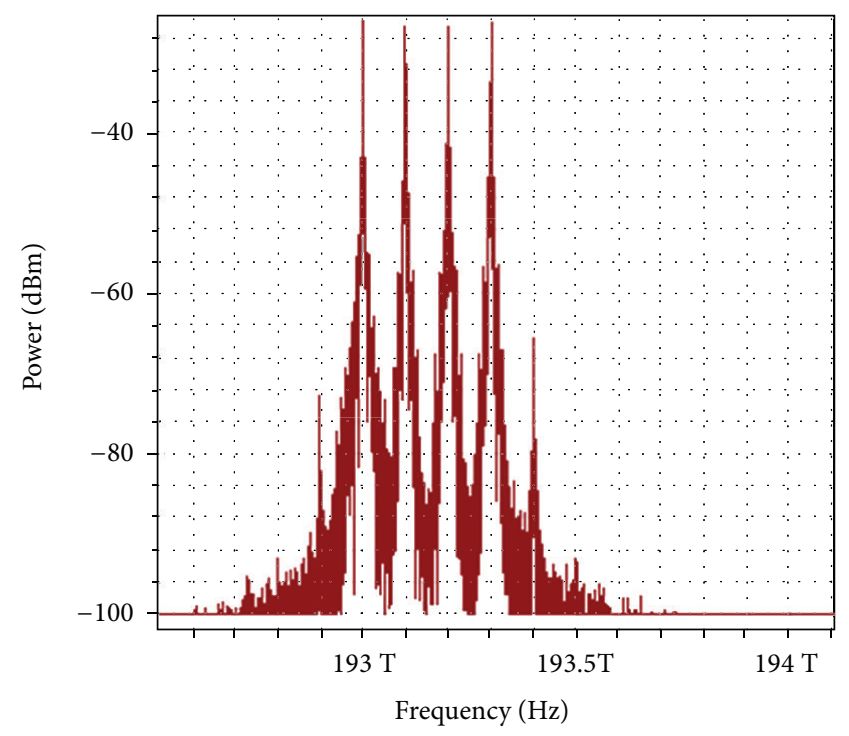

(c)

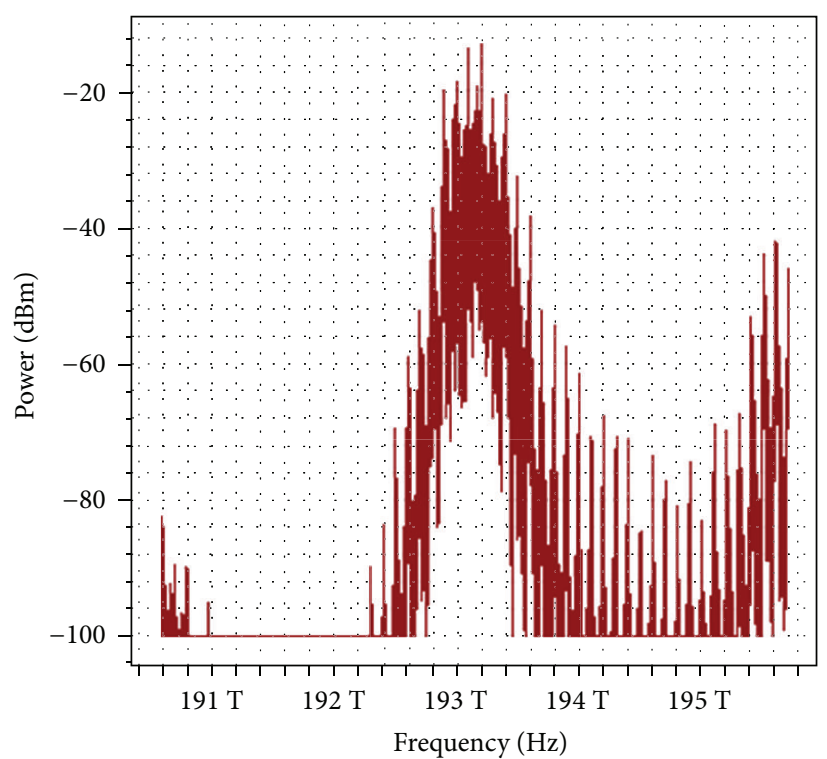

(b)

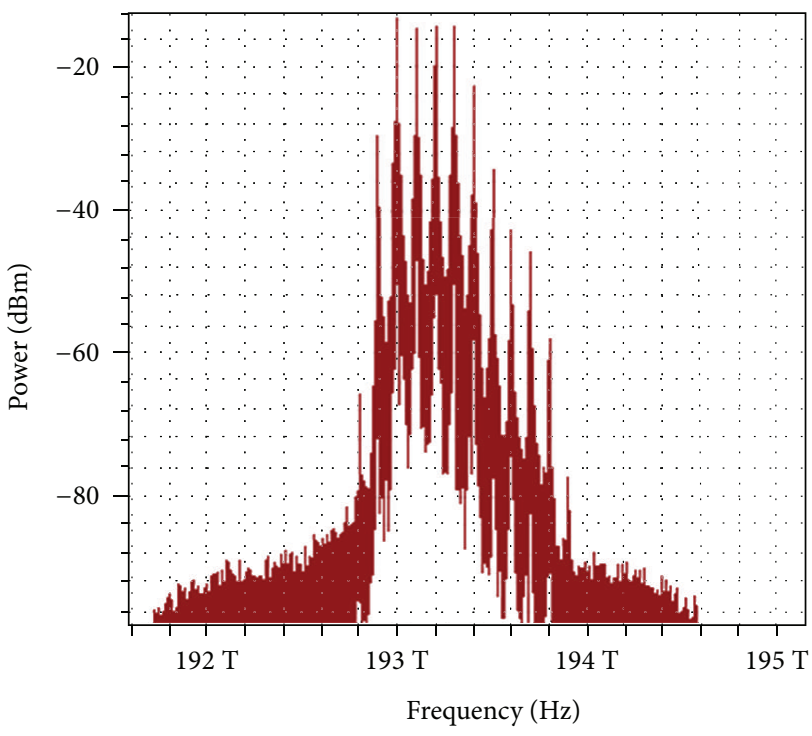

(d)

FIGURE 5: Optical spectrum comparison after $70 \mathrm{~km}$ DSF (a) without polarization technique at input power of $2 \mathrm{dBm}$, (b) without polarization technique at input power of $14 \mathrm{dBm}$, (c) with polarization technique at input power of $2 \mathrm{dBm}$, and (d) with polarization technique at input power $14 \mathrm{dBm}$.

optical fiber ITU-T G.652 was conducted according to the industrial environment protocol in Table 1. Figures 2(a)2(d) illustrate the optical spectrum over a $70 \mathrm{~km}$ optical fiber. Decreasing the input power can decrease the FWM effects. In the absence of the polarization technique, the FWM power was $-56 \mathrm{dBm}$ at an input power of $14 \mathrm{dBm}$, while it was $-64 \mathrm{dBm}$ at a $2 \mathrm{dBm}$ input power. With our proposed technique, the FWM numbers and power are dramatically reduced. The FWM power decreased to less than $-82 \mathrm{dBm}$ at a $2 \mathrm{dBm}$ input power and to $-68 \mathrm{dBm}$ at a $14 \mathrm{dBm}$ input power.

Figures 3(a)-3(d) reveal that the BER in all channels improved with the polarization technique compared with the nonuse of the polarization technique. The BER values at $\mathrm{ch}_{1}, \mathrm{ch}_{2}, \mathrm{ch}_{3}$, and $\mathrm{ch}_{4}$ without the polarization technique were $3.09 \times 10^{-18}, 9.35 \times 10^{-6}, 1.11 \times 10^{-13}$, and $4.69 \times 10^{-7}$ at a received power of $-4.9 \mathrm{dBm}$, respectively. When the polarization technique was used, the system performance, respectively, yielded the minimum BER values of $2.57 \times 10^{-40}$, $9.35 \times 10^{-10}, 4.39 \times 10^{-27}$, and $3 \times 10^{-11}$. Figures $4(\mathrm{a})-4(\mathrm{~b})$ compare the optimum eye diagram with the polarization technique and that without the polarization technique. The former was higher and more optimized than the latter. For $\mathrm{ch}_{1}$, the former was more open (BER of $2.57 \times 10^{-40}$ ) than the latter $\left(\mathrm{BER}\right.$ of $3.09 \times 10^{-18}$ ) at $P_{\text {in }}=14 \mathrm{dBm}$. 


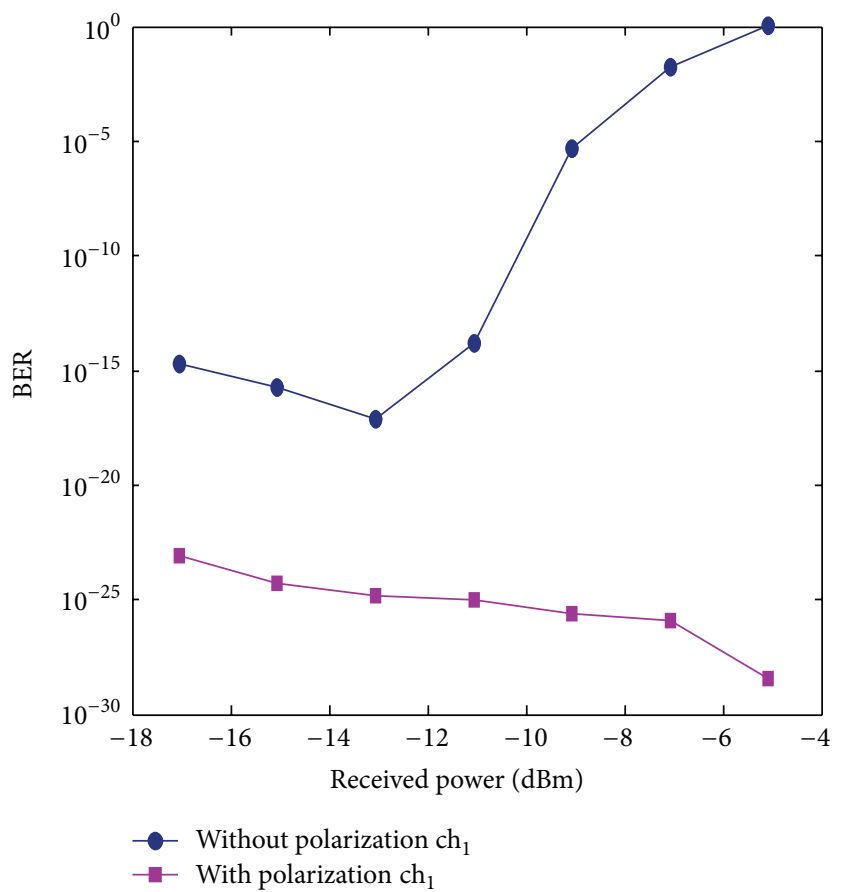

(a)

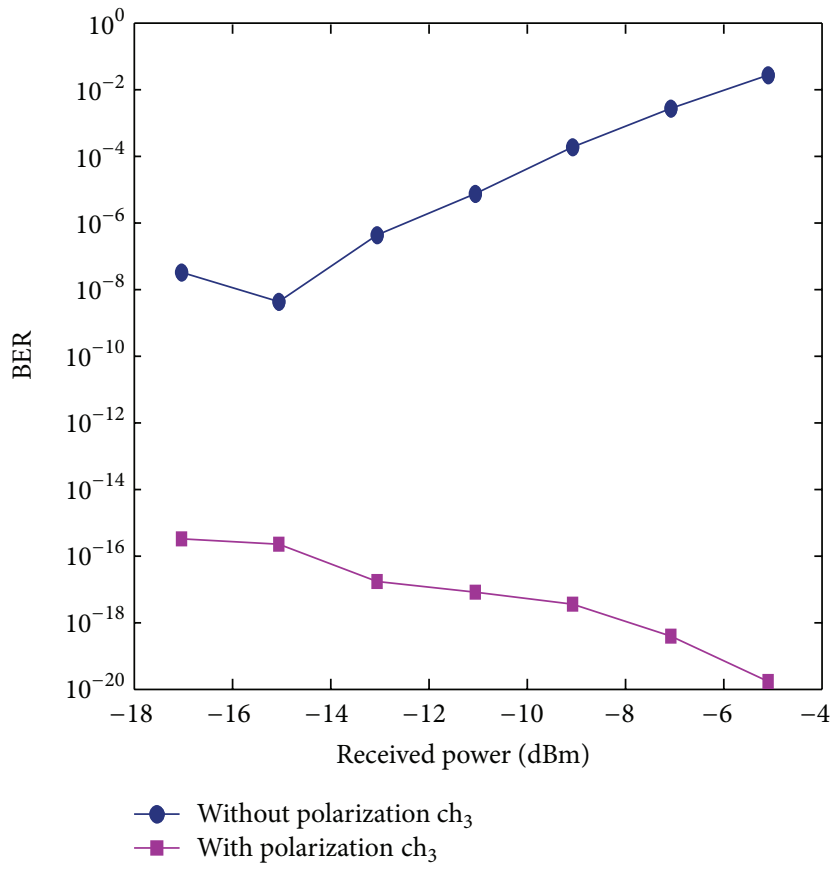

(c)

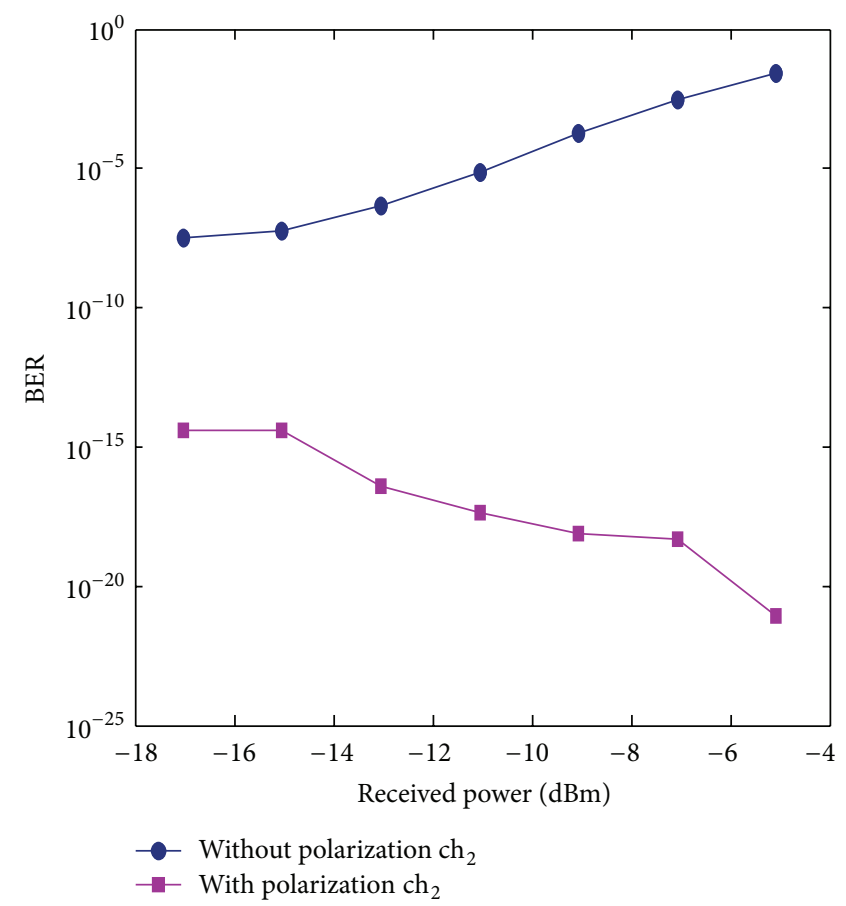

(b)

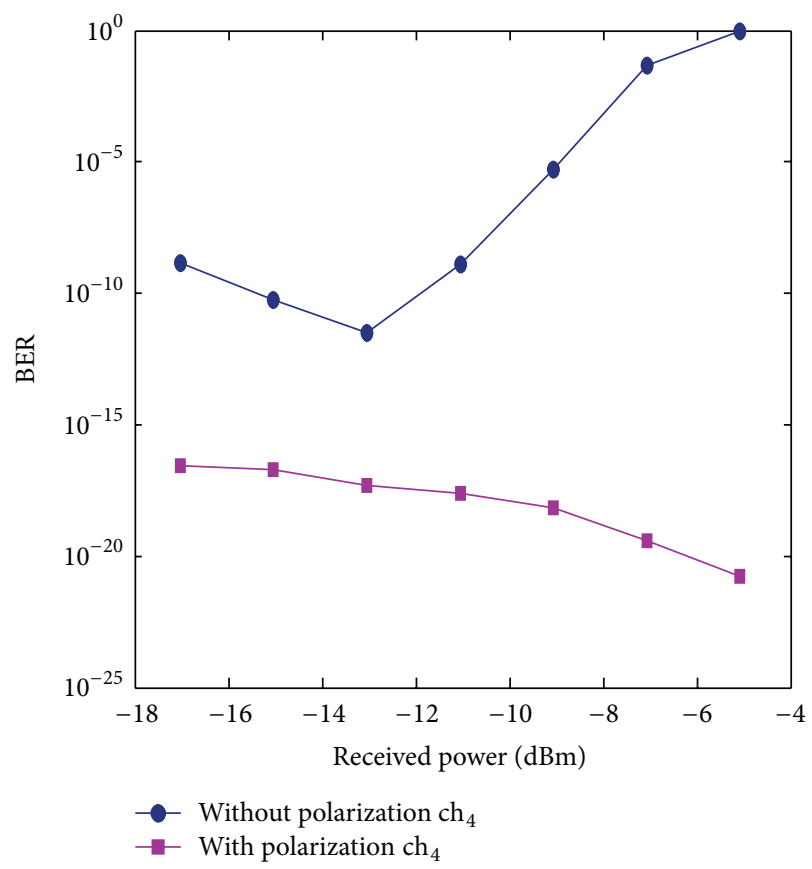

(d)

FIGURE 6: Received power versus BER in the presence and absence of the polarization techniques using DSF at (a) $\mathrm{ch}_{1}$, (b) $\mathrm{ch}_{2}$, (c) $\mathrm{ch}_{3}$, and (d) $\mathrm{ch}_{4}$.

3.2. Effect of Proposed Technique on FWM Behavior and $B E R$ Using DSF. For further investigation, the proposed polarization technique was tested with DSF, using the standard parameters in Table 1. In the DSF, FWM can strongly influence the transmission performance, because most of the FWM interaction occurs near zero dispersion wavelengths.
At a high input power, the FWM crosstalk increased dramatically and superimposed with the transmitted channels. Figure 5 shows that for the conventional system at a $2 \mathrm{dBm}$ input power, the FWM power was $-52 \mathrm{dBm}$. At a high input power of $14 \mathrm{dBm}$, the FWM power significantly increased with the number of FWM interfacing with channels, and 


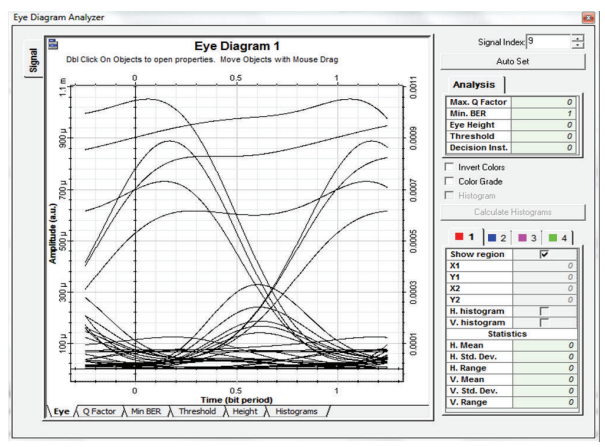

(a)

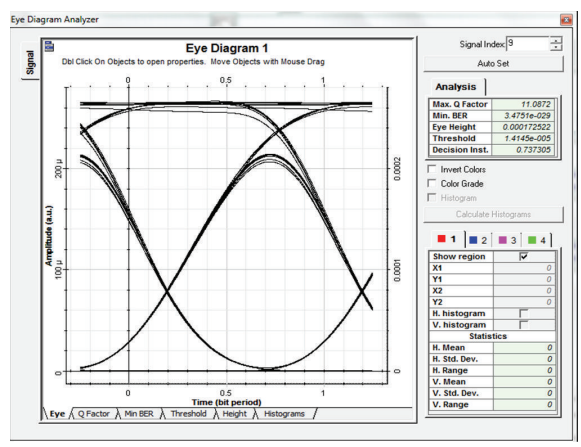

(b)

FIGURE 7: Optimum eye diagram performance of DSF using $\mathrm{ch}_{1}$ (a) without polarization technique and (b) with polarization. Both at $P_{\text {in }}=$ $14 \mathrm{dBm}$.

the FWM power was about $-20 \mathrm{dBm}$. With the proposed polarization technique, most of the FWM frequencies were canceled because the interaction between multiple optical channels that pass through the same fiber reduced, which suppressed the FWM. At 2 and $14 \mathrm{dBm}$ input powers, the FWM powers were -69 and $-25 \mathrm{dBm}$, respectively.

The overlapping between the transmitted channel and the FWM crosstalk was translated into a distorted signal and detected by the receiver, which led to the significant degradation of the system performance. Figure 6 show the BER pattern using DSF, with and without the polarization technique. With lower input power, BERs decreased with increasing received signal power. At a received power of $-17.03 \mathrm{dBm}$, the BERs at $\mathrm{ch}_{1}, \mathrm{ch}_{2}, \mathrm{ch}_{3}$, and $\mathrm{ch}_{4}$ are $3.4 \times 10^{-15}$, $4 \times 10^{-8}, 3 \times 10^{-8}$, and $1.6 \times 10^{-9}$, respectively. With the polarization technique, the BERs are respectively $7.3 \times 10^{-24}$, $3.9 \times 10^{-15}, 3 \times 10^{-16}$, and $2.8 \times 10^{-17}$.

With the increase of the input power, the FWM power also increased and more FWM crosstalk superimposed with channels, which affected the transmitted channel. BER increased as the received signal power decreased and the noise power increased. For example, at a high input power of $14 \mathrm{dBm}(-13.84 \mathrm{dBm}$ received power), the BERs were $1,0.05$, 0.033 , and 1 at $\mathrm{ch}_{1}, \mathrm{ch}_{2}, \mathrm{ch}_{3}$, and $\mathrm{ch}_{4}$ with the conventional technique, respectively. The system performance drastically improved in the presence of the polarization technique, where the BER values were respectively $3.4 \times 10^{-29}, 8 \times 10^{-22}$, $1.6 \times 10^{-20}$, and $1.8 \times 10^{-21}$. Based on these findings, the polarization approach introduces a dramatic durability for reducing the FWM crosstalk, even at high input power and low dispersion. In terms of the eye diagram, the first channel revealed a high and optimum eye diagram in the proposed technique than in the conventional one.

Figures 7(a)-7(b) illustrate the eye diagram using DSF for both techniques at a $14 \mathrm{dBm}$ input power. The polarization technique was superior to the conventional technique at high input power values.

\section{Conclusion}

In this paper, we propose an efficient approach for reducing the transmission limitation caused by the FWM in a WDM system by using the pairing combinations of differently linear-polarized optical signals. The FWM behavior and system performance were evaluated with the proposed technique under the input power parameter and using two kinds of optical fiber, namely, SMF and DSF. The FWM powers were suppressed to less than -68 and $-25 \mathrm{dBm}$ at a $14 \mathrm{dBm}$ input power in the presence of this approach using the SMF and DSF, respectively. The polarization technique also enhanced the BERs in the range of $2.57 \times 10^{-40}$ and $3.47 \times 10^{-29}$ at received powers of -4.90 and $-13.84 \mathrm{dBm}$ for SMF and DSF, respectively. The findings prove that the polarization approach significantly reduced the FWM crosstalk through fiber transmission. The obtained results also show that in the existence of the polarization approach, the FWM crosstalk has no dangerous effect, even with a high input optical power of $14 \mathrm{dBm}$.

\section{Conflict of Interests}

The authors declare that there is no conflict of interests regarding the publication of this paper.

\section{Acknowledgment}

The authors would like to thank the Ministry of Higher Education Malaysia for funding this project under the Exploratory Research Grant no. ERGS/1/2013/STG02/ UNITEN/02/01.

\section{References}

[1] A. R. Chraplyvy, "Limitations on lightwave communications imposed by optical-fiber nonlinearities," Journal of Lightwave Technology, vol. 8, no. 10, pp. 1548-1557, 1990.

[2] H. J. Abed, N. M. Din, M. H. Al-Mansoori, H. A. Fadhil, and F. Abdullah, "Recent four-wave mixing suppression methods," Optik, vol. 124, no. 15, pp. 2214-2218, 2013.

[3] C. Wehmann, L. Fernandes, C. Sobrinho et al., "Analysis of the four wave mixing effect (FWM) in a dispersion decreasing fiber (DDF) for a WDM system," Optical Fiber Technology, vol. 11, no. 3, pp. 306-618, 2005.

[4] M. Jamshidifar, A. Vedadi, and M. E. Marhic, "Reduction of four-wave-mixing crosstalk in a short fiber-optical parametric 
amplifier," IEEE Photonics Technology Letters, vol. 21, no. 17, pp. 1244-1246, 2009.

[5] H. J. Abd, M. H. Al-Mansoori, N. M. Din, F. Abdullah, and H. A. Fadhil, "Priority-based parameter optimization strategy for reducing the effects of four-wave mixing on WDM system," Optik, vol. 125, no. 1, pp. 25-30, 2014.

[6] R. Kaler and R. S. Kaler, "Investigation of four wave mixing effect at different channel spacing," Optik, vol. 123, no. 4, pp. 352-356, 2012.

[7] K. Inoue, "Arrangement of orthogonal polarized signals for suppressing fiber four-wave mixing in optical multichannel transmission systems," IEEE Photonics Technology Letters, vol. 3, no. 6, pp. 560-563, 1991.

[8] J. Onishi, S. Kojima, and T. Numai, "Effects of frequency/polarization allocations and the zero-dispersion frequency on FDM lightwave transmission systems," Optics Communications, vol. 281, no. 14, pp. 3882-3891, 2008.

[9] J. Onishi, S. Kojima, and T. Numai, "Effects of frequency and polarization allocations on FDM lightwave transmission systems," Optics Communications, vol. 281, no. 9, pp. 2627-2632, 2008.

[10] K. Inoue, "Polarization effect on four-wave mixing efficiency in a single-mode fiber," IEEE Journal of Quantum Electronics, vol. 28, no. 4, pp. 883-894, 1992.

[11] H. J. Abed, N. M. DIN, M. H. Al-Mansoori, F. Abdullah, and H. A. Fadhil, "A new FWM reduction technique based on damping selective wavelengths," Ukrainian Journal of Physics, vol. 58, no. 10, pp. 956-961, 2013. 

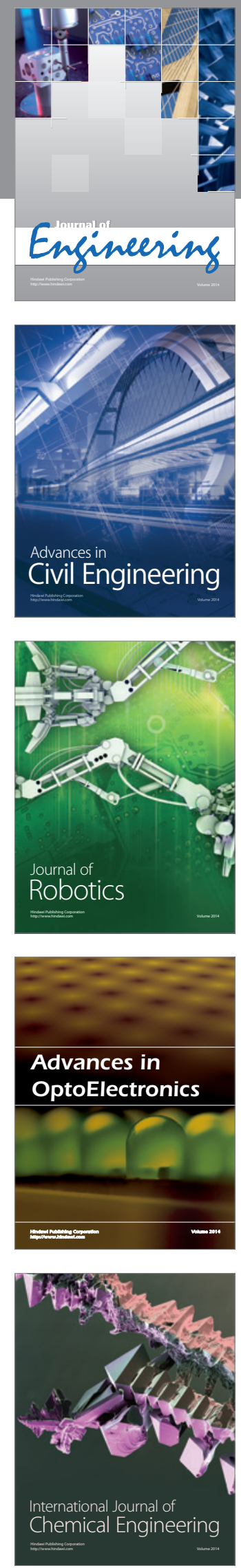

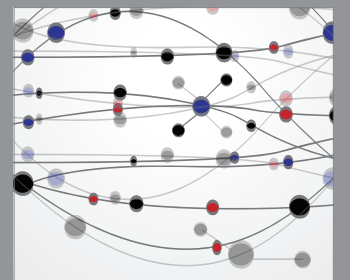

The Scientific World Journal
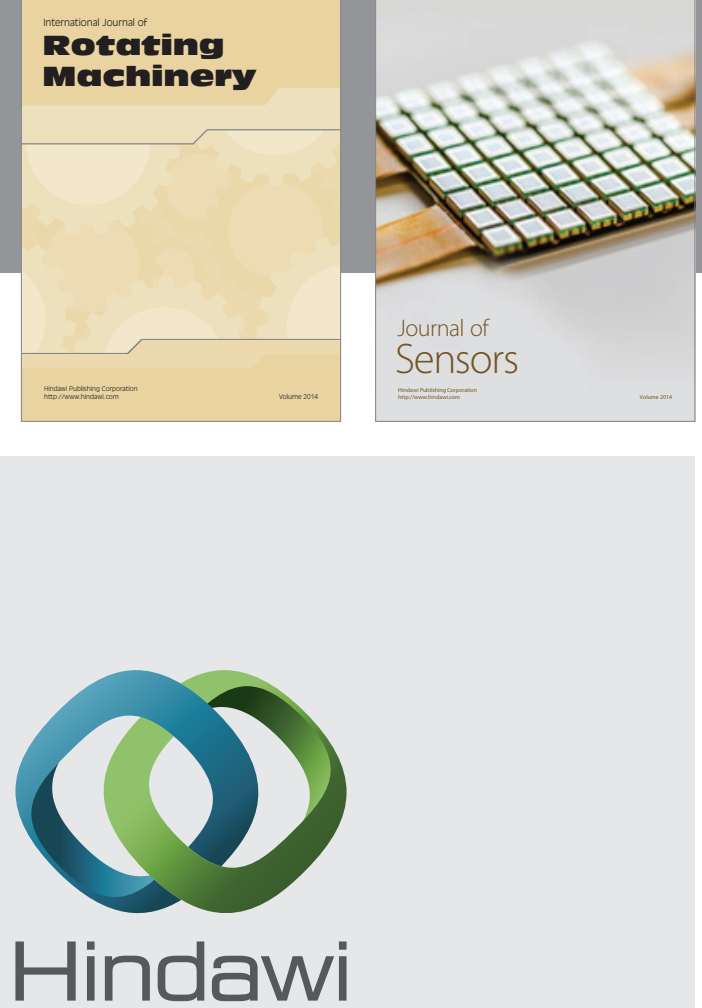

Submit your manuscripts at http://www.hindawi.com
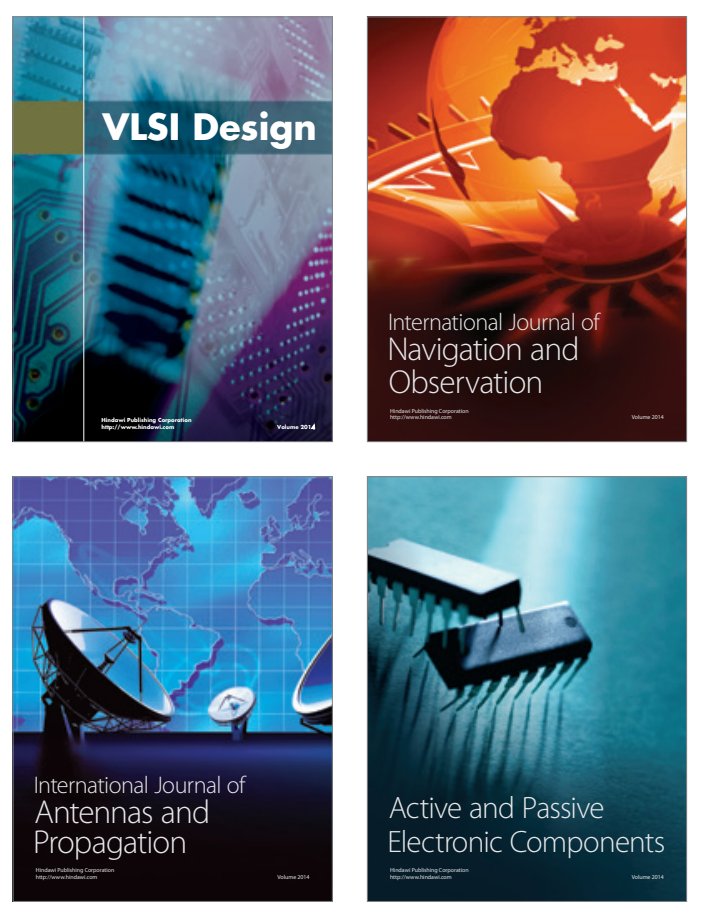
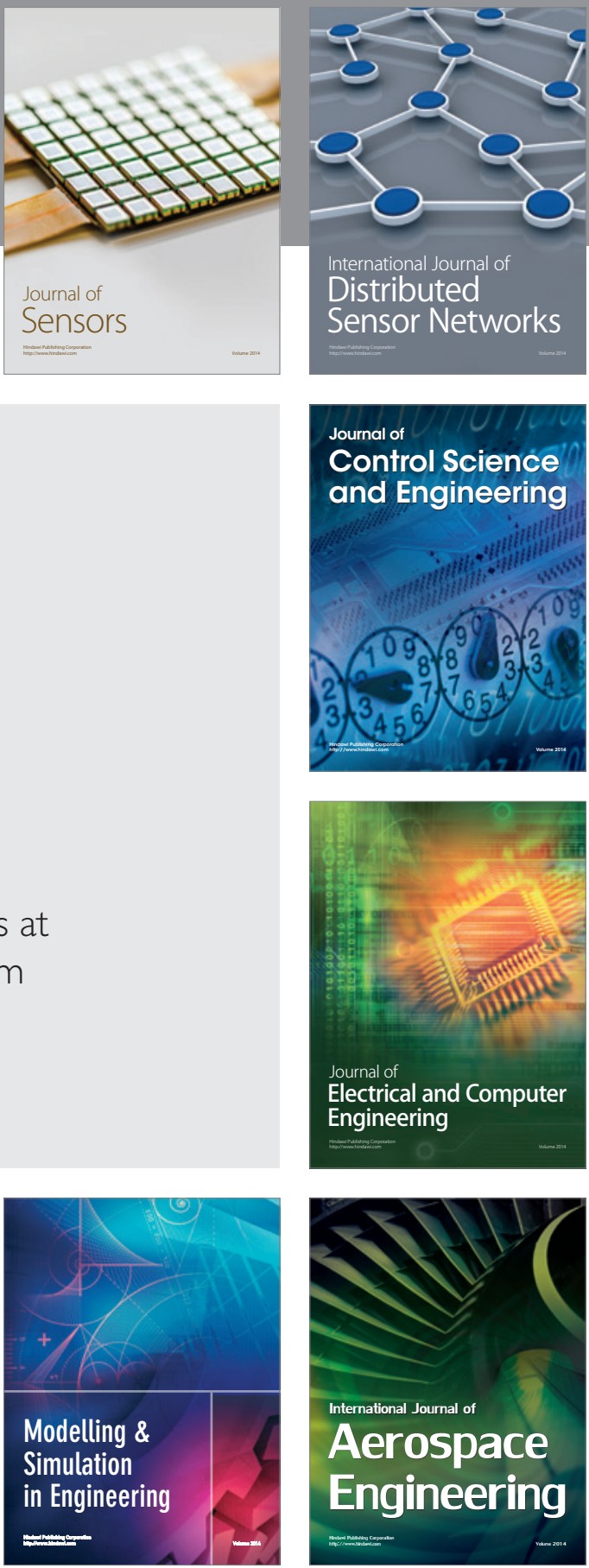

Journal of

Control Science

and Engineering
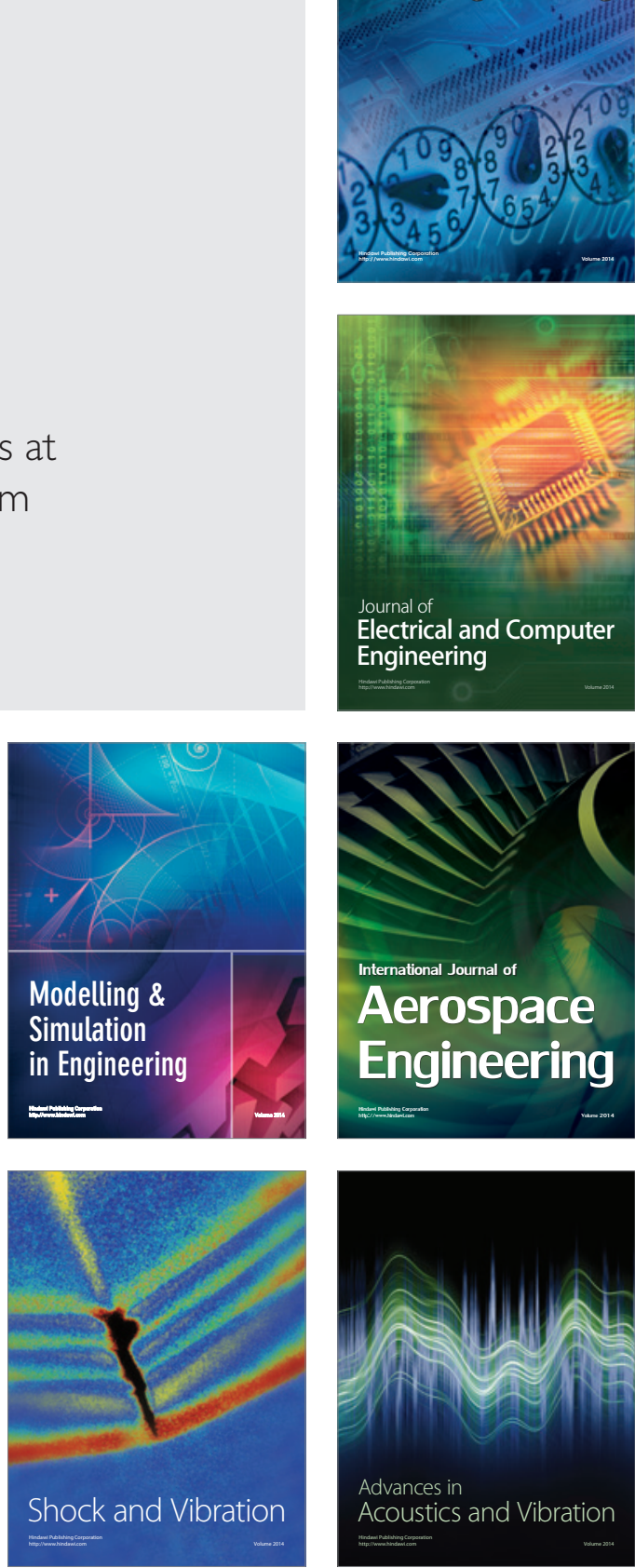